\title{
Relationship between Acromiohumeral Distance, and Glenohumeral Internal Rotation Deficit in Patients with Shoulder Impingement Syndrome
}

\author{
ALAA A.H. BALBAA, P.h.D.*; HATEM M. EL-AZIZI, M.D.**; MOHAMMED A. SARHAN, P.h.D.*** and \\ MANAR OBBAHA, M.Sc.*
}

The Departments of Musculoskeletal Disorders and their Surgeries*, Faculty of Physical Therapy, Diagnostic Radiology**, Faculty of Medicine, Cairo University, Cairo and Musculoskeletal Disorders and Its Surgery***, Faculty of Physical Therapy, South Valley University, Egypt

\begin{abstract}
Background: A loss of glenohumeral internal rotation has been associated with altered kinematics of the glenohumeral and the scapulothoracic joint.

Aim of Study: To evaluate the association between Acromio-humeral distance (AHD), gleno-humeral internal rotation deficit GIRD).

Methods: 40 impingement patients (from 25 to 45 years old), participated in this study, They were evaluated by ultrasonography for acromio-humeral distance(AHD), digital goniometer for gleno-humeral internal rotation deficit (GIRD).

Results: This study showed a positive significant relation between gleno-humeral internal rotation difict (GIRD) and acromio-humeral distance (AHD), GIRD increase, AHD decrease.

Conclusion: Glenohumeral internal rotation deficit, decrease acromiohumeral distance and lead to compression of the rotator cuff and subacromial bursa in this limited space in patients with shoulder impingement syndrome.
\end{abstract}

Key Words: Impingement syndrome - Acromiohumeral distance - Posterior capsule tightness.

\section{Introduction}

SHOULDER impingement syndrome (SIS) is a narrowing of the suacromial space (SAS) compressing rotator cuff, biceps tendon long head, and suacromial bursa Within it, against anterior under surface of the acromio and coracoacromial ligament during elevation of the arm, impingement on the tendinous portion of the rotator cuff by the coracoacromial ligament and the anterior third of the acromion is responsible for a characteristic syndrome of disability of the shoulder [1].

Correspondence to: Dr. Manar Obbaha, The Department of Musculoskeletal Disorders and their Surgeries, Faculty of Physical Therapy, Cairo University
Shoulder impingement accounts for 44 to $65 \%$ of shoulder Complaints during physician visits [2]

Shoulder pain and dysfunction is a complex problem frequently encountered by primary care physicians. Common nonarthritic conditions seen in the primary care setting include rotator cuff syndrome, impingement, posttraumatic stiffness, adhesive capsulitis, and instability. Pain and instability are the most common shoulder complaints. Pain that is sharp or burning is commonly radicular in origin, whereas pain caused by tendinitis is often dull, diffuse, and aching. Instability is frequently found in patients with a history of dislocation, but also may occur with no prior history [3]

The most common soft tissue inflexibility is glenohumeral internal rotation deficit (GIRD), it was approved that individuals with impingement syndrome have substantially more GIRD than healthy control subjects $[4,5]$, positive relationship between glenohumeral IR deficit and abnormal scapular positioning(increased anterior tilt and decreased upward rotation with humeral IR from $90^{\circ}$ abduction) was identified [6]

The subacromial space was quantified by the (AHD) that was defined as the distance between the infero-lateral edge of acromion and the apex of the greater tubercle [7].

Musculoskeletal shoulder ultrasonography is an established validated diagnostic imaging modality for the evaluation of clinically suspected rotator cuff disorders.

In concordance with recent increased use, it was found that musculoskeletal shoulder US has 
a substantial impact on patient treatment and the decision making of clinicians [8].

\section{Patients and Methods}

The study was performed at Kasr El-Aini Outpatients Clinic and Ahmed Maher governmental hospital Cairo, Egypt, it extended from September 2016 to August 2018, Ethical approval was obtained by the ERC of faculty of physical therapy on September 2016.

\section{Study design: Associated study.}

Subject: Forty patients, with the age ranged from ( 25 to 45 ) years old, was referred by orthopedist as unilateral shoulder impingement syndrome stage II (Neer's classification), The patients had three of six from impingement criteria, which was as follows:

1- The patient had a positive "Neer sign".

2- The patient had a positive "Hawkins sign".

3- The patient had pain with active shoulder elevation in the scapular plane.

4-The patient had a history of pain in the C5-C6 dermatome.

5- The patient had pain with palpation of the rotator cuff tendons.

6-The patient had pain with resisted isometric abduction [9]

\section{Inclusion criteria:}

- Patients from 25to 45 years old, female and male

- Patients will be in stage I, II of impingement syndrome Neer classification 1983 (mechanical cause)

- 3 of 6 of impingement criteria.

- Normal posture.

\section{Exclusion criteria:}

- History of shoulder instability (positive Sulcus sign, positive apprehension test and history of shoulder dislocation.

- History of symptoms related to cervical spine.

- History of acrmioclavicular pain.

\section{Instrumentation:}

1- Ultrasonography (AHD) Diagnostic ultrasound equipment (Toshiba, Otawara, Japan). For measuring acromiohumeral distance (AHD), Fig. (1B).

2- Nclinometer (baseline ${ }^{\circledR}$ bubble inclinometer. Fabrication Enterprises INC, white plains, New york 10602, USA) was used for assessing active internal rotation range of the shoulder joint, Fig. (1A).

\section{Assessment procedures:}

\section{1- ADH Measurement:}

Sonographic images were obtained by a single investigator, specialized in shoulder ultrasonography,Subjects? positions was standardized and corrected before the start of ultrasound scanning. They were seated upright without back support, with their feet flat on the ground. When we scan the subacromial space at 0 degree of shoulder abduction, subjects asked to keep their arms relaxed along their body with the ulnar side of their hand supported on their thighs and the thumbs pointing upward [10-13], Fig. (2).

When imaging the subacromial space at 45 and 60 degrees of shoulder abduction, subjects had to actively keep their arm in this position with the elbow flexed 90 degrees and the hand in neutral position with the thumb pointing upward, the transducer was positioned in the coronal plane, parallel with the long axis of the humerus [10-14], Fig. (2).

\section{2- Internal rotation range of motion:}

Each patient had to place in a supine position on a flat level surface with arm abducted in 90 and the inclinometer was fixed above wrist, one examiner had to position above the patient to properly stabilize the scapula during testing by applying a posteriorly directed force to the coracoid to avoid scapular compensation by palpating the coracoid (with the examiner's thumb) and the spine of the scapula (with the examiner's fingers). This method has been shown to more accurately control for scapular movements compared with putting the full hand on the shoulder during the measurement and the other examiner read the measurement, ask the patient to internally rotate the arm actively to the limit of pain [15-18], as shown in Fig. (3).

The digital inclinometer was zeroed by using a fixed horizontal (measurements 9-11) or vertical (measurements 12 and 13) reference point, depending on the measurement, to ensure accuracy. Then, the inclinometer was placed dorsally or ventrally midway on the forearm, depending on movement direction [19], Fig. (3).

\section{Statistical analysis:}

\section{Descriptive statistics:}

Data will be collected and analyzed using mean, standard deviation Arithmetic mean will be used as an average describing the central tendency of observations. 
The standard deviation as a measure of dispersion of results around mean, multiple regression analysis for independent variable which isgleno-
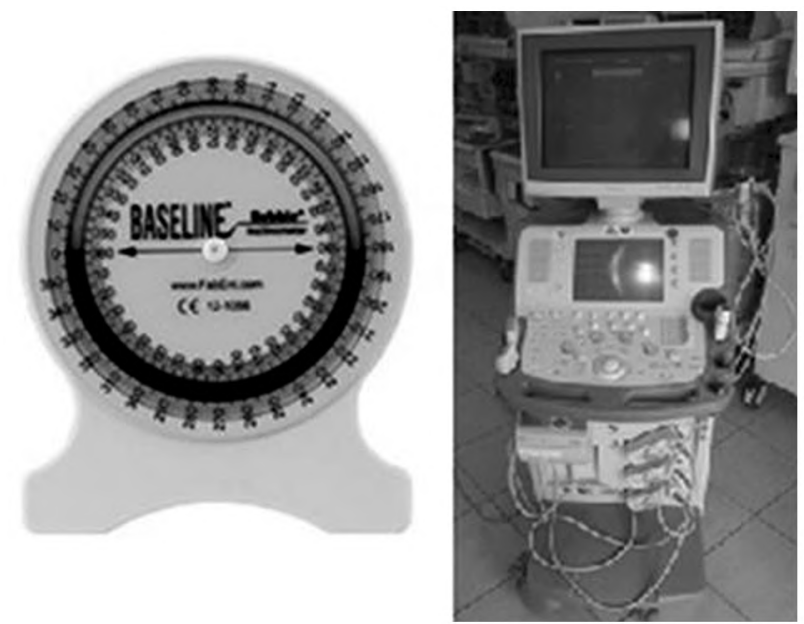

Fig. (1): Instruments; (A): Baseline bubble inclinometer. The blue color is the moving fluid within the inclineometer, (B): Diagnostic ultrasound equipment. humeral internal rotation deficit (GIRD) and depedent variable which is acromiohumeral distance (AHD).
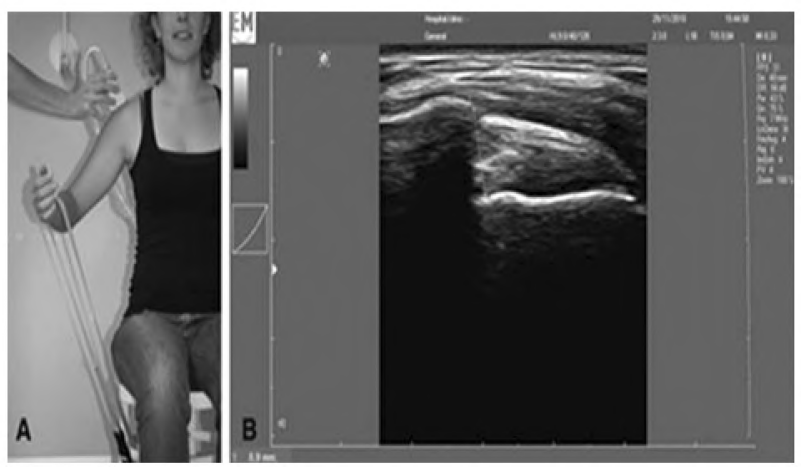

Fig. (2): Left: Subject position and probe placement during ultrasound imaging of the subacromial space. Right: Measurement of the acromiohumeral distance on ultrasound image. Adopted [10]

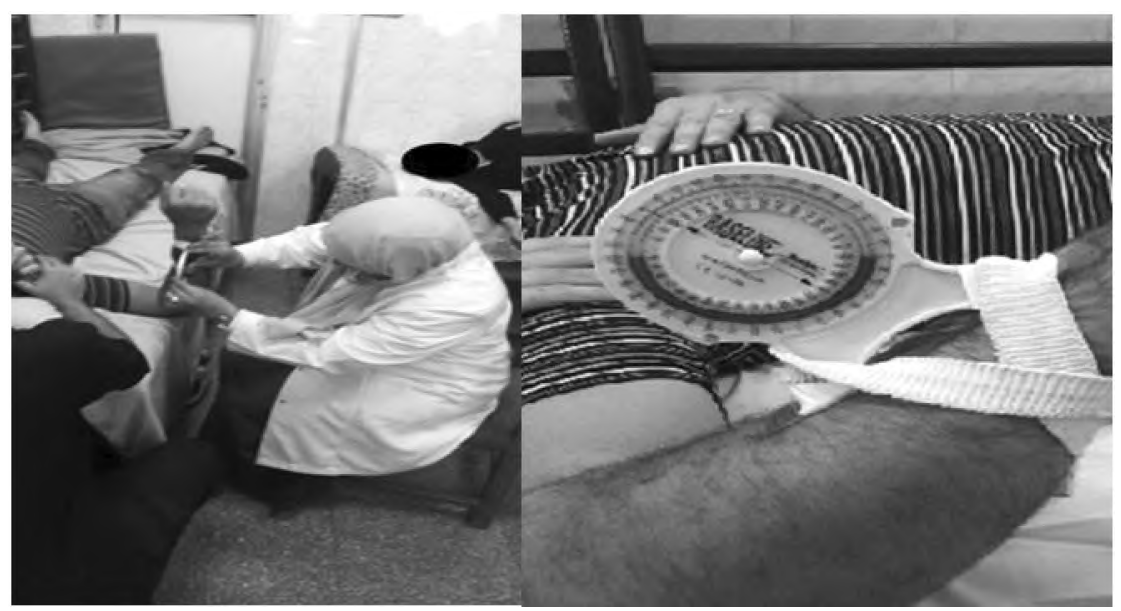

Fig. (3): Measurement of active internal rotation range of motion.

\section{Results}

Person correlation coefficient analysis for relation between dependent variables (affected AHD), and independent variables [affected IR (GIRD)].

Regression analysis for slope line regression equation between dependent variables (affected AHD), and independent variables [affected IRGIRD)], Significant level: All statistical analyses were significant at 0.05 level of probability $\left(p^{<}\right.$ $0.05)$.

The regression analysis of the data show significant effect of internal rotation deficit on ac- romiohumeral distance (AHD) at rest and in abduction $\left(\mathrm{y}=0.068 \mathrm{x} 1+4.450, \mathrm{y}^{\wedge}=0.039 \mathrm{x} 2+3.882\right)$, respectively, ( $p$-values) were $0.016,0.021$, respectively, see Table (1).

The relation between the Gleno-humeral internal rotation deficit and acromiohumeral distance decrease was significant, the relation was positive, when internal rotation range of motion decrease, the acromio-humeral distance decrease $(r)$ values in (position 1), (position 2), 0.64, 0.72 respectively. With $p$-value in the (position 1), (position 2), 0.013, 0.004 , respectively, see Table (2). 
Table (1): Regression between affected Internal Rotation (glenohumeral internal rotation deficit) and acromiohumeral distance (AHD).

\begin{tabular}{lcccc}
\hline Item & AHD & $\begin{array}{c}\text { Regression } \\
\text { equation }\end{array}$ & $\begin{array}{c}p \text { - } \\
\text { value }\end{array}$ & Significant \\
\hline $\begin{array}{l}\text { Affected IR } \\
\text { (GIRD) }\end{array}$ & $\begin{array}{c}\text { Position (1) } \\
\text { at rest }\end{array}$ & $\begin{array}{c}\mathrm{y}^{\wedge}=0.068 \times 1 \\
+4.450\end{array}$ & 0.016 & $\mathrm{~S}$ \\
& $\begin{array}{c}\text { Position (2) } \\
\text { abduction }\end{array}$ & $\begin{array}{c}\mathrm{y}^{\wedge}=0.039 \times 2 \\
+3.882\end{array}$ & 0.021 & $\mathrm{~S}$ \\
& & & \\
\hline
\end{tabular}

$\mathrm{y}^{\wedge}$ : Independent variable dyskinesis (position 1- at rest).

$\mathrm{x} 1$ : Dependent variable (AHD position 1- at rest).

x2: Dependent variable (AHD position 2-abduction).

Table (2): Correlation between affected Internal rotation (glenohumeral internal rotation deficit) (Gird) and acromiohumeral distance (AHD).

\begin{tabular}{lcccc}
\hline Item & AHD & $\begin{array}{c}\text { Correlation } \\
\text { coefficient }(r)\end{array}$ & $\begin{array}{c}p \text { - } \\
\text { value }\end{array}$ & Significant \\
\hline $\begin{array}{l}\text { Affected IR } \\
\text { (GIRD) }\end{array}$ & $\begin{array}{c}\text { Position (1) } \\
\text { at rest } \\
\text { Position (2) } \\
\text { abduction }\end{array}$ & 0.64 & 0.013 & $\mathrm{~S}$ \\
& 0.72 & 0.004 & $\mathrm{~S}$ \\
\hline
\end{tabular}

$p$-value: Probability. $\quad \mathrm{S}$ : Significant.

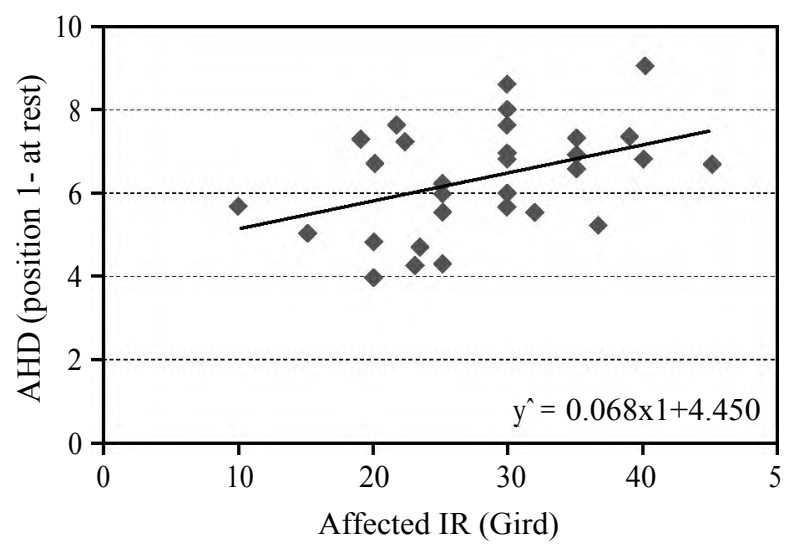

Fig. (4): Show correlation between affected Ir (Gird) and AHD (position 1- at rest).

\section{Discussion}

The results of the current study approved that increase glenohumeral internal rotation deficit ( $p$ value $=0.021$ ) leads to decrease in acromiohumeral distance, the results of this relationship may be attributed to imbalance between internal rotation and external rotation which attributed to posterior capsule tightness and humeral retroversion lead to shifting humeral head instant center of rotation to anterior superior position on glenoid [20-24]

Furthermore imbalance between internal rotation and external rotation which attributed to pos- terior capsule tightness and humeral retroversion lead to shifting humeral head instant center of rotation to anterior superior position on glenoid [20-24]

The findings of the present study regarding significant relation between gleno-humeral internal rotation deficit and acromio-humeral distance decline agree with findings of [10] who illustrated that decreased AHD at the dominant side with GIRD and a combined increase of internal rotation ROM and AHD after stretching that suggest there is an association, the results of this study showed a smaller AHD at the dominant side of overhead athletes with a GIRD of more than 15 degree.

In addition to that, [25] showed that flexion with external and internal rotations resulted in contact of the CA arch with the supraspinatuse subscapularis and supraspinatuse infraspinatus regions, respectively.

The results of the present study promote the outcomes of the study of $[\mathbf{2 6 , 2 7 ]}$ who reported different rotation positions during Neer impingement sign maneuver led to inconsistency in their findings, These findings suggest that humeral rotation position affects the site where peak contact pressure occurs.

The findings of the current study agree with work of [4] who demonstrated that a loss of almost 22 of internal rotation motion in patients with subacromial impingement, and also with [10] who illustrated that decreased AHD at the dominant side with GIRD and a combined increase of internal rotation ROM and AHD after stretching that suggest there is an association.

The results of present study are reinforced with [28] who demonstrated that the acromiohumeral distance was significantly larger with internal rotation of the humerus. The results may be attributed to the subscapularis, an internal rotator, aids the activities of the latissimus dorsi, pectoralis major, and the teres major, it provides medial rotation of the humerus. This enhances, the activity of the anterior and posterior fibers of the deltoid, the triceps long head, the teres major, and the pectoralis major and triggers adduction, of the humerus, thereby increasing the acromiohumeral distance. The increase in the acromiohumeral distance decreased pressure on the subhumeral acromial space, The larger size of the subhumeral acromial space during internal rotation is due to the internally rotated muscles triggering inferior translation of the humerus increasing the space. 


\section{Conclusion:}

There is significant relationship between Glenohumeral internal rotation deficit and acromiohumeral distance, it caused decline the acromiohumeral space which result in compression of the rotator cuff and subacromial bursa in this limited space in patients with shoulder impingement syndrome.

\section{References}

1- NEER C.S., 2ND: Anterior acromioplasty for the chronic impingement syndrome in the shoulder: A preliminary report. J. Bone Joint Surg. Am., 54 (1): 41-50, 1972.

2- MICHENER L.A., WALSWORTH M.K. and BURNET E.N. : Effectiveness of rehabilitation for patients with Subacromial impingement syndrome: A systematic review. Journal of Hand Therapy, 17 (2): 152-164, 2004.

3- HOLMES R.E., BARFIELD W.R. and WOOLF S.K. Clinical evaluation of nonarthritic shoulder pain: Diagnosis and treatment. ThePhysician and Sportsmedicine, 43 (3): 262-268, 2015.

4- TYLER T.F., NICHOLAS S.J., ROY T. and GLEIM G.W. Quantification of posterior capsuletightness and motion loss in patients with shoulder impingement. Am. J. Sports Med., 28 (5): 668-673, 2000.

5- MYERS J.B., LAUDNER K.G., PASQUALE M.R., BRADLEY J.P. and LEPHART S.M.: Glenohumeral range of motion deficits and posterior shoulder tightness in throwers with pathologic internal impingement. Am. J. Sports Med., 34: 385-91, 2006.

6- BORICH M.R., BRIGHT J.M., LORELLO D.J., CIEMINSKI C.J., BUISMAN T. and LUDEWIG P.M.: Scapular angular positioning at end range internal rotation in cases of glenohumeral internal rotation deficit. J. Orthop. Sports Phys. Ther., 36: 926-934, 2006.

7- CHOLEWINSKI J.J., KUSZ D.J., WOJCIECHOWSKI P., et al.: Ultrasound measurement of rotator cuff thickness and acromio-humeral distance in the diagnosis of subacromial impingement syndrome of the shoulder. Knee Surg. Sports Traumatol. Arthrosc., 16: 408-414, 2008.

8- MICHAEL V. FRIEDMAN, TRAVIS J. HILLEN, DAVID V. HOLLAND, JAMES M. ESSENBERG and JENNIFER L. DEMERTZIS: Impact of Shoulder Sonographyon Clinical Decision Making, 2017 by the American Institute of Ultrasound in Medicine. J. Ultrasound Med., 00: 00-00 0278-4297, 2017.

9- LUKASIEWICZ A.C., McCLURE P., MICHENER L., PRATT N. and SENNETT B.: Comparison of 3dimensional scapular position and orientation between subjects with and without shoulder impingement. J. Orthop. Sports Phys. Ther., 29: 574-583; discussion 584586, 1999.

10- MAENHOUT A., VAN EESSEL V., LIESELOT VAN DYCK, AAGJE VANRAES and ANN COOLS: Quantifying Acromiohumeral Distance in Overhead Athletes With Glenohumeral Internal Rotation Loss and the Influence of a Stretching Program, Am. J. Sports Med., 2012.

11- DESMEULESF, MINVILLE L., RIEDERER B., COTE C.H. and FREMONT P.: Acromiohumeral distance variation measured by ultrasonography and its association with the outcome of rehabilitation for shoulder impingement syndrome. Clin. J. Sport Med., 14: 197-205, 2004.

12-KALRA N., SEITZ A.L., BOARDMAN N.D., et al.: Effect of posture on acromiohumeral distance with arm elevation in subjects with and without rotator cuff disease using ultrasonography. J. Orthop. Sports Phys. Ther., 40 (10): 633-640,2010.

13- LEONG H.T., TSUI S., YING M., LEUNG V. and SIU N. FU: Ultrasound measurements on acromio-humeral distance and supraspinatus tendon thickness: Test-retest reliability and correlations with shoulder rotational strengths. Science and medicine in sport J., 15 (4): 284 $291,2012$.

14- SILVA R.T., HARTMAN L.G., De SOUZA LAURINO C.F., et al.: Clinical and ultrasonographic correlation between scapular dyskinesia and subacromial space measurement among junior elite tennis players. Br. J. Sports Med., 44: 407-410, 2010.

15- WILK K.E., REINOL M.M, C. MACRINA L.C., RON PORTERFIELD, DEVINE K.M., SUAREZ K. and JAMES ANDREWS J.R.: Glenohumeral Internal Rotation Measurements Differ Depending on Stabilization Techniques. Sports Healt, 1 (2): 13 1-136, 2009.

16- NORKIN C.C. and WHITE D.J. Measurement of Joint Motion: A Guide to Goniometry. $3^{\text {rd }}$ ed. Philadelphia: F.A. Davis Company, 2003.

17- KIBLER W.B., SCIASCIA A.D. and MOORE S. : An acute throwing episode decreases shoulder internal rotation. Clin. Orthop. Relat. Res., 470 (6): 1545-51, 2012(A).

18- KIBLER SCIASCIA A. and THOMAS S.J.: Glenohumeral Internal Rotation Deficit: Pathogenesisand Response to Acut Throwing.Sports Med. Arthrosc. Rev., 20 (1): 348. 2012(B).

19- COOLS A.M., De WILDE L., VAN TONGEL A., CEYSSENS C., RYCKEWAERT R. and CAMBIER D.C.: Measuring Shoulder External and Internal Rotation Strength and Range of Motion: Comprehensive Intra-Rater and Inter-Rater Reliability Study of Several Testing Protocols. Journal of Shoulder and Elbow Surgery, 23: 1454-1461, 2014.

20- BURKHART S.S., MORGAN C.D. and KIBLER W.B.: The disabled throwing shoulder: Spectrum of pathology part III: The SICK scapula, scapular dyskinesis, the kinetic chain, and rehabilitation. Arthroscopy, 19: 641-661, 2003.

21- BURKHART S.S., MORGAN C.D. and KIBLER W.B.: The disabled throwing shoulder: Spectrum of pathology. PartI: Pathoanatomy and biomechanics, Arthroscopy, 19 (4): 404-420, 2003

22- GROSSMAN M.G., TIBONE J.E., MCGARRY M.H., et al.: A cadaveric model of the throwing shoulder: A possible etiology of superior labrum anterior-to-posterior lesions. J. Bone Joint Surg. Am., 87: 824-83 1, 2005.

23- HUFFMAN G.R., TIBONE J.E., MCGARRY M.H., et al.: Path of glenohumeral articulation throughout the rotational range of motion in a thrower's shoulder model. Am. J. Sports Med., 34: 1662-1669, 2006.

24- CLABBERS K.M., KELLY J.D. IV, BADER D., EAGER M., IMHAUSER C., SIEGLER S., et al.: Effect of posterior 
capsule tightness on glenohumeral translation in the latecocking phase of pitching. J. Sport Rehabil, 16: 419, 2007.

25- YAMAMOTO N., MURAKI T., SPERLING J., STEINMANN S., ITOI E., COFIELD R., et al.: Impingement mechanisms of the Neer and Hawkins signs. Journal of Shoulder and Elbow Surgery, 18: 942e7, 2009.

26- PAPPAS C., BLEMKER S., BEAULIEU C., MCADAMS

T., WHALEN S. and GOLD G.: In vivo anatomy of the Neer and Hawkins sign positions for shoulder impinge- ment. Journal of Shoulder and Elbow Surgery, 15: 40e9, 2006.

27- ROBERTS C., DAVILA J., HUSHEK S., TILLET E. and CORRIGAN T.: Magnetic resonance imaging analysis of the subacromial space in the impingement sign positions. Journal of Shoulder and Elbow Surgery, 11 (6): 595e9, 2002.

28- KIM H., KIM B., SHIM J., KWON H. and JUNG J.: Comparative Analysis of Acromiohumeral Distances According to the Locations of the Arms and Humeral Rotatio. J. Phys. Ther Sci. Jan., 26 (1): 97-100, 2014.

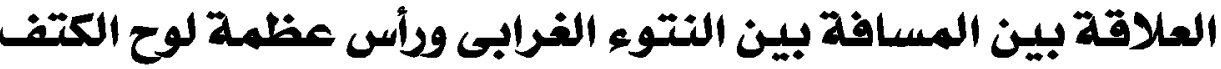

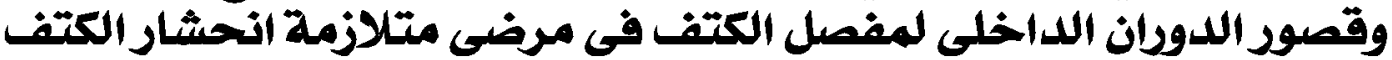

\footnotetext{
الخلفية: يعتبر قصود الدودان الداخلى من أهم أسباب تغير ميكانيكية مفصل الكتف وحدوث متلازمة انحشار الكتف.

الغرض : التحقق من تأثير والعلاقة بين قصور الدوان الداخلى لحركة مفصل الكتف والمسافة بين النتوء الغرابى ودأس عظمة لوح الكتف.

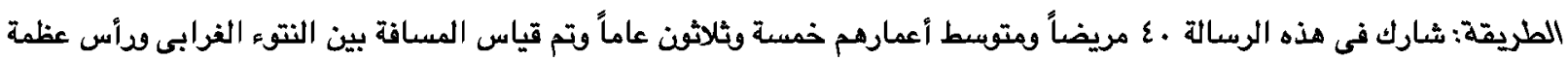
لوح الكتف بالأشعة الصوتية وقصود الدودان الداخلى لمفصل الكتف بجهاز قياس المدى الحركى.

النتائج: أثبتت نتائج الدراسة وجود علاقة إيجابية مؤكدة بين قصود الدودان الداخلى لمفصل الكتف والمسافة بين النتوء الغرابى ودأس

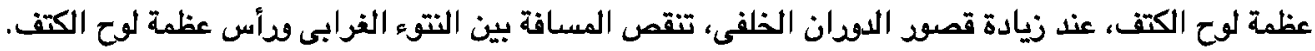

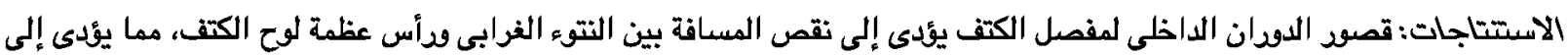
انحشار العضلات فى المسافة بين النتوء الغرابى رأس عظمة لوح الكتف الصغيرة فئ حالات مرضى متلازمة انحشار الكتف.
} 